$32^{\text {nd }}$ European Modeling \& Simulation Symposium

$17^{\text {th }}$ International Multidisciplinary Modeling \& Simulation Multiconference

\title{
Design Of Railway Network Model Reflecting Data Structure Non-Oriented Graph Using Oracle Spatial Database For Simulation Of Traffic
}

\author{
Jan Fikejz ${ }^{1, *}$ \\ ${ }^{1}$ Department of Software Technologies, FEI, University of Pardubice, Pardubice, Czech Republic \\ ${ }^{*}$ Corresponding author. Email address: jan.fikejz@upce.cz
}

\begin{abstract}
This article deals with the design of a multilayer railway network model reflecting data structure non-oriented graph. Attention is firstly paid to motivation for using the railway network model to identify the rolling stock position, further, to describe railway infrastructure, its appropriate data representation and defining abstraction of the model considered. Subsequently the article focuses on algorithms enabling to build a multilayer railway network model with the use of base data files. The designed model reflects the data structure non-oriented graph and is implemented directly in Oracle database with the use of the Oracle Spatial and Graph technology. In the conclusion of the article we focus on the use of the railway network model in the rolling stock localization segment using computer simulation.
\end{abstract}

Keywords: Railway infrastructure models, railway infrastructure models, train positioning, railway traffic simulation

\section{Introduction}

With regard to the railway infrastructure identification of the rolling stock (train vehicle) position is one of the areas of rail transport. The current knowledge of the position enables processing of a whole range of procedures ranging from safety to providing operational information to the passengers. To successfully carry out the localization, it is necessary to design:

- relevant model of the railway network infrastructure

- appropriate technical solution of pairing the information on current location of the rolling stock with the infrastructure model.

Based on the importance and utilization rate of the lines various localization systems can then be applied with variable reliability and accuracy. Regional lines are not as important subject of interest as the main or international corridors, nevertheless in each country regional lines form a substantial part of the railway network. These lines have their specifics, including a. o. the fact that they often consist of single-track railways, have lower utilization rate, lower speed limits, but also lower requirements for control and localization systems. In 2011 the European Commission issued a white paper (Kom, 2011) defining goals and operations for the transport sector with the outlook until 2050. This white paper a. o. determines a plan of a single European transport area - Creating a competitive and resource efficient transport system. From the rail transport perspective, it concerns especially reinforcement of the rail transport on the main as well as regional lines and introducing intelligent systems using e.g. ERTMS (European Rail Traffic Management

(C) 2020 The Authors. This article is an open access article distributed under the terms and conditions of the Creative Commons Attribution (CC BY-NC-ND) license (https://creativecommons.org/licenses/by-nc-nd/4.0/). 
System) or GNSS (Global Navigation Satellite System). Also, with regard to this perspective, appropriate attention should be paid to regional lines.

\section{State of Art}

\subsection{ERTMS Regional - Sweden}

This system was developed in cooperation with the International Union of Railways (UIC), Swedish Transport Administration (Trafikverket) and the Bombardier company (Giuninho, 2014). ERTMS Regional is a simpler and cheaper variant of the ERTMS/ETCS L1 to L2, presenting an appropriate variant for the lines with lower traffic density. The proposed system is operated on a single-track line with the total length of $143 \mathrm{~km}$ with five stations and transportation density of 16 trains per day, whereas further extension to lines with the total length of 565 $\mathrm{km}$ is planned. The main principle consists in periodical (every 6 seconds) transmission of information on location to the radio block center (Train Control Centre) TCC, which issues running permits. The information on the rolling stock location is obtained from odometer, and more precise localization is realized by means of balises installed in stations and on tracks with fixed spacing of $5 \mathrm{~km}$. The GSM-R and GSM mobile networks are used for the information transmission.

\subsection{LOCOPROL - France}

Another system, used in France, is the LOCOPROL technological solution (Libbrecht and Sturesson, 2005), with the abbreviation derived from the full name Low Cost Satellite based train location system for signaling and train Protection for Low density traffic railway lines. The system was developed under the direction of the ALSTOM company and other partners from Belgium, Germany, and France within a research project focused on the utilization of satellite navigation for lines with low traffic density. The LOCOPOROL system is used on a single-track regional line in the length of $35 \mathrm{~km}$. The main principal again uses the Radio Block Centre (RBC), to which information on rolling stock location on the line is transmitted, and running permits are also issued by the RBC. Information on the rolling stock position is determined by means of satellite navigation (GPS, Glonass, in the future also Galileo) and odometer. More precise localization in critical spots (usually in stations and deviated tracks, or in places with radio shadow) is realized by means of the balises installed. The positioning locator is integrated directly into the onboard ECTS device and the mobile network of a public operator is used for the information transmission. The integrity of the train is controlled by the driver.

\subsection{InSat - Italy}

A system called 3InSat (Train Integrated Safety Satellite System) was developed in Italy under the auspices of the Ansaldo STS company in cooperation with other partners from abroad. The project was finalized in 2014 and the resulting system is used on a single-track regional line in Sardinia with the total length of $50 \mathrm{~km}$. RCB is used here again to collect location data and issue running permits. The information on the rolling stock location is obtained from the satellite navigation (GPS EGNOS, Galielo) and odometer. The mobile network GSM, TETRA (TransEuropean Trunked Radio) and satellite communication is used to transmit the information. The architecture of the solution is based on ETCS L2 (Mouna, 2013)

\subsection{SATLOC - Romania}

The SATLOC system was established under the auspices of UIC in cooperation with eleven organizations from six countries around the world with the support of the European Space Agency (ESA). The project focuses on the development and innovative use of GNSS to support rail traffic management within regional lines. Furthermore, the objectives of the project are focused on the design of new operational standards, software and hardware solutions and services.

Currently, the SATLOC system is operated in test mode on a single-track line in the length of $27 \mathrm{~km}$. The designed and tested system meets the ETCS L2 standards (Redding, 2014).

\subsection{Current situation in the Czech Republic}

The infrastructure of the Czech railway network currently disposes of over nine and a half thousand kilometers of lines, which are divided into four categories (see Figure 1):

- corridor lines registered in the European railway system with the total length of $1,402 \mathrm{~km}$ - pink colour;

- national lines registered in the European railway system with the total length of $1,189 \mathrm{~km}$ - green colour;

- national lines not registered in the European railway system with the total length of $3,748 \mathrm{~km}-$ red colour;

- regional lines not registered in the European railway system with the total length of 3,232 km blue colour.

Single-track lines account for approximately 7,607 $\mathrm{km}$, which corresponds with approximately $80 \%$ of the total length of all lines. The regional lines as such account for over 33\% of all lines (Dorazil, 2014; Kolář,2014). 


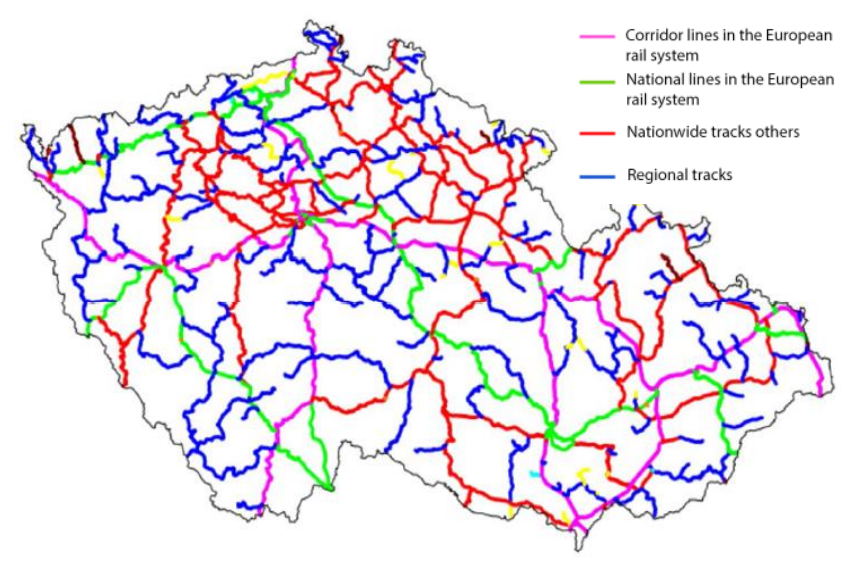

Figure 1: Line structure in the Czech Republic.

With regard to lower utilization rate, single-track lines and, especially, regional lines are perceived as less important, and this is connected with a lower level of control. On these lines it is often only possible to register that the train left the station or arrived at the station. Despite of that, hundreds of emergency situations have occurred over the last decade.

\section{Description of the infrastructure}

To build a railway network model it is necessary to dispose of appropriate data, upon which the model could be built with a certain degree of abstraction. In experiments it was found out, that we can proceed from stationing data (distance markers) when designing a railway network model. Stationing or distance markers are physical elements placed in the trackage of the railway infrastructure (approximately after $100 \mathrm{~m}$ ), and each stationing disposes of GPS coordinates a. 0 . These data do not precisely describe the complete railway network infrastructure (especially in stations), nevertheless they can be used to design a model. Further, based on an analysis of data provided by SŽDC-TUDC (Správa železniční dopravní cesty Technická ústř́edna dopravní cesty, Railway Transport Route Management - Technical Transport Route Centre) it was evaluated that the following four datasets are sufficient for the design of representation of the railway network:

- sheet of stationing/distance markers and TUDUs;

- sheet of supertracks;

- sheet of railway stations;

- sheet of definition supersections.

The key link between the particular sheets is always TUDU (line definition section). In a simplified way we can say that individual supertracks consist of definition supersections, where each supersection embraces line definition sections (TUDUs) with distance markers. Figure 2 presents the overall depiction of the main aspects of the railway network description.

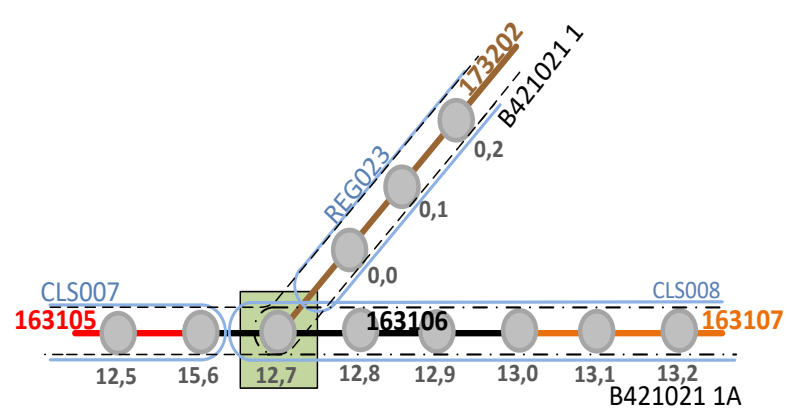

Figure 2: Methodology of the railway network description

Distance markers are depicted in the figure with the distance in kilometers and are represented by means of grey points. TUDUs are registered using a six-figure code $(163105,163106,16307,173202)$, and are represented by solid lines (red, black, orange, brown). The particular supersections (CLS 007, CLS008, REG023) are depicted in light blue and supertracks (B421021 1, and B421021 1A) are represented by dashed lines. The point significant from the traffic perspective (branching of lines) is symbolized by a green square.

The above-mentioned way of viewing the infrastructure is related to the environment of the Czech Republic, nevertheless a similar approach, or a variation thereof, could be applicable also outside the Czech Republic, as the distance markers occur on lines in other European countries as well.

\section{The design and implementation of the railway network model}

Generally, for transport infrastructure modelling mathematical structures graph, as they are defined in the theory of graphs and related algorithms are used with advantages. From the perspective of the processed domain's character it is possible to use a non-oriented graph, as the traffic on the individual railway segments (represented by edges) can be organised in any direction. Generally, a graph can e.g. be built in a operating memory with the use of appropriate data structures, or a specialized database tool can be used, that supports work with graph representations.

\subsection{Graph implementation in a database with the support of multidimensional data}

A graph representation can not only be built in a standard relational database (e.g. MSSQL, MySQL or Oracle), nevertheless it is also possible to use sophisticated graph databases (belonging to the NoSQL group) offering a whole range of graph algorithms with high computing efficiency.

The Oracle database from version 8.1.5 offers the possibility to work with multidimensional data using the Spatial technology (Kothuri et al., 2007; Kothuri, R. et al. 2007). For the work with spatial data Oracle defines a special object data type SDO_GEOMETRY. 
This data type enables keeping a whole range of spatial information, and geometrical types, such as various points, arches, linear chains and polygons. From version 11 the Oracle database enables using other superstructures, which apart from working with multidimensional data enable building network and graph topologies - under the current name Oracle Spatial and Graph. To index spatial data the Oracle database uses R-tree structure. Version $12 \mathrm{c}$ brings even significant indexation speedup by means of the Vector Performance Acceleration technology, thanks to which some of the spatial functions and operations are up to fifty times faster than in previous versions. Figure 3 show the structure of the Network Data Model technology.

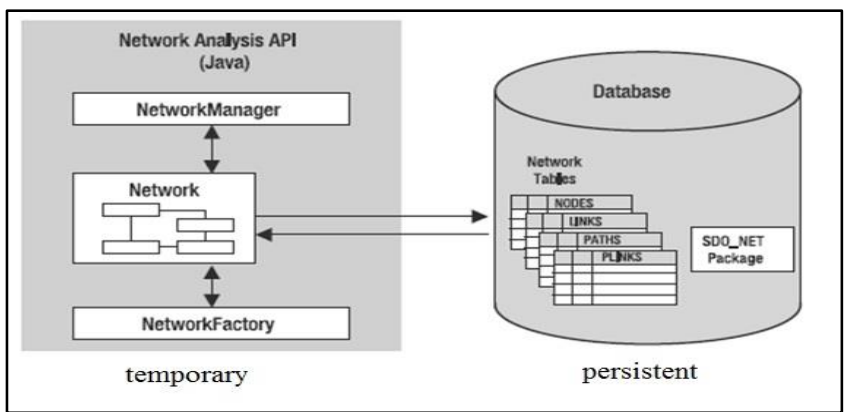

Figure 3: Structure of the Network Data Model technology. (Murray et al., 2006)

\subsection{Algorithms for the design of the railway network infrastructure models}

The final model includes three data layers:

- Data-Micro, consisting of vertices and edges,

- Data-Mezo, include mezo-vertices and mezoedges

- Data-Macro, containing super-vertices and superedges.

The above layers are described in the following subsections.

\subsubsection{Construction methodology of the Data-Micro model layer}

The first data layer (Data-Micro) reflects physical railway network infrastructure - with the lowest abstraction rate, and the particular vertexes of the model/graph correspond with the distance markers. Data obtained from the import from the input files unfortunately do not reflect the entirely realistic image of the railway network infrastructure, especially in stations with more tracks. If a station disposes of ten tracks for example (transport tracks as well as reserve tracks), the input data files can for example only include three tracks. In addition, in most of the cases these tracks do not converge in stations anyhow and go further to the following station.

Generally, the methodology of building the lowest layer can be sum up into three main steps:

1. Creating substitutional vertexes - The first part of the algorithm focuses on substitutional vertexes construction, especially in railway stations with more tracks. In the second part of the algorithm distance markers that have not been used within the substitutional vertices construction are filled into the set of vertexes, figure 4 .

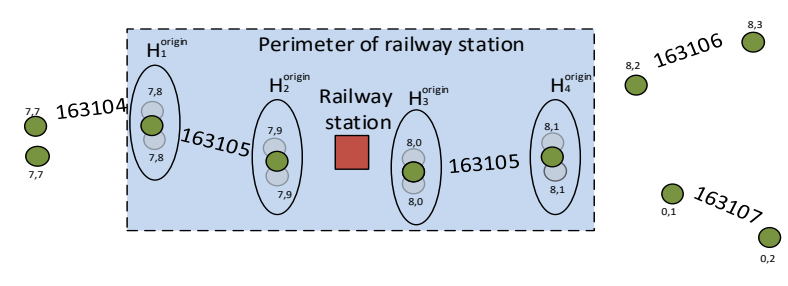

Figure 4: Illustration of the result of the vertexes creation algorithm.

2. Edge construction within the individual TUDUs, which is the next step for creation of the first data layer of the Data-Micro model.
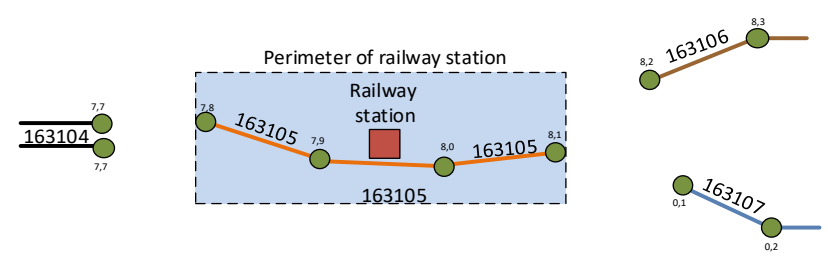

Figure 5: Edge construction within particular TUDUs

3. Edge creation between neighboring TUDUs - is probably the most demanding operation within the process of building the railway network model from the base data. The problem proceeds from the above-mentioned error rate, and in certain cases from indefiniteness in the input data. The goal of the algorithm is the edge construction between the individual TUDUs connecting the bordering distance markers.

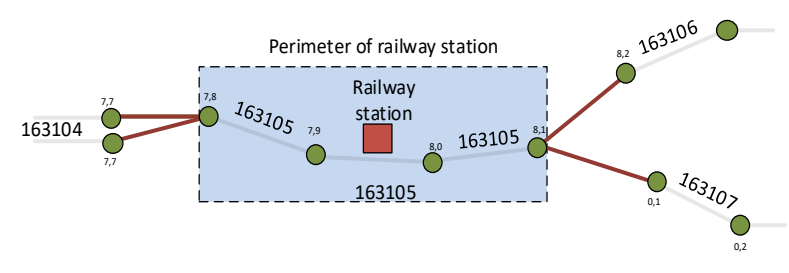

Figure 6: Creating edges between various TUDUs 


\subsubsection{Building the layer of the Data-Makro model}

Another layer of the railway network model, DataMakro, with the highest abstraction rate proceeds from the first layer of the model (Data-Micro) and introduces a coarser granularity. On this level we introduce the expressions super-edge and supervertex.

Super-vertex is such a vertex from the Data-Micro layer, that coincides with more than two edges.

A super-edge connects two super-vertexes. In other words, it replaces progression of edges in the microlayer in a section, where no track crossing, converging of tracks into one or diverging into more tracks occur.

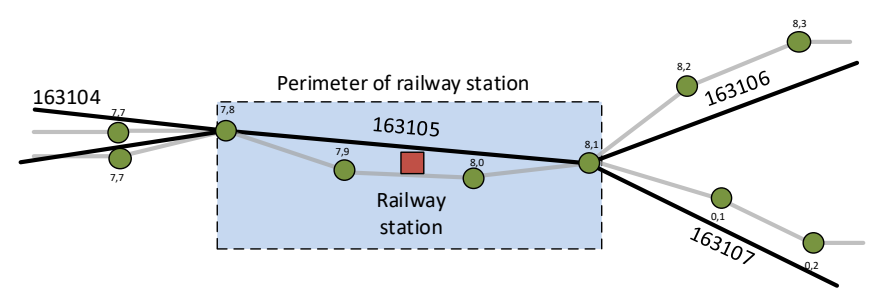

Figure 7: Building the layer of the Data-Makro model

\subsection{Concept of the Data-Mezo model layer}

In the first data layer (Data-Micro) the edges evaluation corresponds with the lengths of $100 \mathrm{~m}$, whereas in the second data layer with a higher abstraction rate (Data-Makro) the edges evaluation can reflect distances of up to tens of kilometers. Both of these data layers (Data-Miro and Data-Makro) do not directly include railway stations as their vertexes, and there was an alternative way of identification of e.g. whether the rolling stock is in the station or not, or what is its distance from the station (by means of TUDU identification, to which each railway station is affiliate). We aim for reflecting this fact in the third data layer Data-Mezo by means of decomposition of the individual super-edges.

Figure 8 depicts data layers Data-Micro and DataMakro, and railway stations.

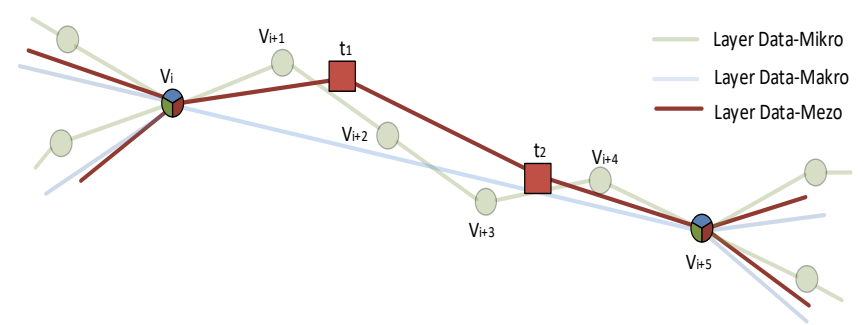

Figure 8: Depiction of the Data-Mezo data layer in the context of the Data-Micro and Data-Makro layers.

\section{Identification of the rolling stock position on the railway network with the use of the Oracle Spatial database}

By means of the above-mentioned algorithms, and with the use of the data obtained, it is possible to build a three-layer railway network model with various abstraction levels. The final model is subsequently saved in the Oracle database with the Network Data Model technology (Oracle Spatial and Graph), which enables building the graph representation directly on the level of the database machine. To achieve proper functioning, it is however necessary to complement the database structure of the model by relational sheets in a way which would keep hierarchy of the individual layers. Vertexes and edges of the graph are saved in predefined database sheets and are complemented by the respective geometrical characteristics (point, straight line), which are kept in a special objectrelational data type SDO GEOMETRY. The vertexes are represented by multidimensional points with GPS coordinates. The edges are then realized as line segments between particular vertexes. For the work with this object-relational data type the Oracle database offers a whole range of functions and operators, such as for example calculation of the distance of two objects, localization of the nearest object from the defined object (e.g. a point), or identification of the intersection of two geometric objects.

The design of our own approach to localization of the rolling stock on a line proceeds from proper pairing of the GPS information on vehicle position (obtained from communication terminals, which send the information on the current position of the rolling stock every 30 seconds) with the closest vertex and edge of the graph. The identified vertex/distance marker disposes of not only multidimensional key in the form of a GPS coordinate, but by means of the definition sections (TUDUs) it is connected to other information related to the railway infrastructure.

For the realization of this approach to localization of the rolling stock we use the SDO NN (nearest neighbor) operator (Kothuri, R. et al. 2007) which identifies the geometrical object that is the closest from the defined object (e.g. a point). In other words, it is possible to find the vertex, or the edge in the model, that is the closest from the current position of the rolling stock

The detection of the rolling stock's current position itself can be divided into the following steps:

1. identification of the nearest vertex and edge of the graph - from the rolling stock's current position related to the three-layer railway network model

2. relevancy evaluation of the incoming GPS information from the communication terminal verification of whether the current position is free from inappropriate errors (e.g. that the distance of 
the rolling stock from the nearest vertex/edge only amounts to units to tens of meters, or that a rolling stock is still assigned to the same superedge on condition that it should still occur there).

3. calculation of accurate position of the rolling stock on a model edge - using perpendicular projection of a point (current position of the rolling stock) on a line (axis of the identified edge/track)

Figure 9 shows the distances of the current rolling stock position from the nearest vertices and edge of the infrastructure

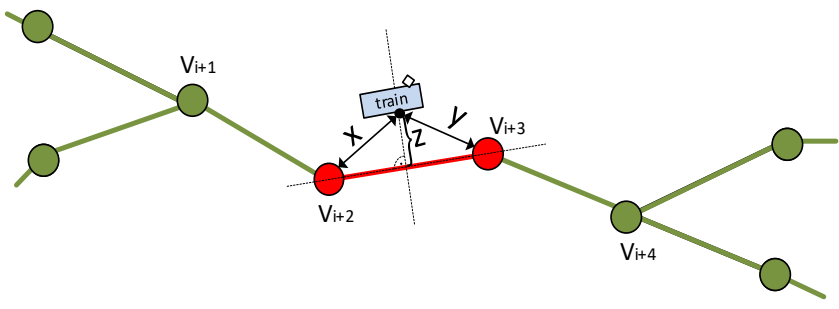

Figure 9: Illustration of the distances of the current RS position from the nearest vertices and edge of the infrastructure.

\section{Visualization}

If we consider visualization of the railway network infrastructure model, we need to take into account the way of multidimensional data storage. In the case of using the Oracle database with Spatial technology the MapViewer visualization tool (Murray, Ch, et al., 2010) developed in Java can be used for the visualization. MapViewer is a J2EE service for depicting supporting maps proceeding from spatial data (e.g. object data type SDO GEOMETRY) administered by means of Oracle Spatial. This technology can be used for establishing scalable mapping layers with various level of detail of the depicted information. Basic concept of the MapViewer tool architecture is depicted in figure 10.

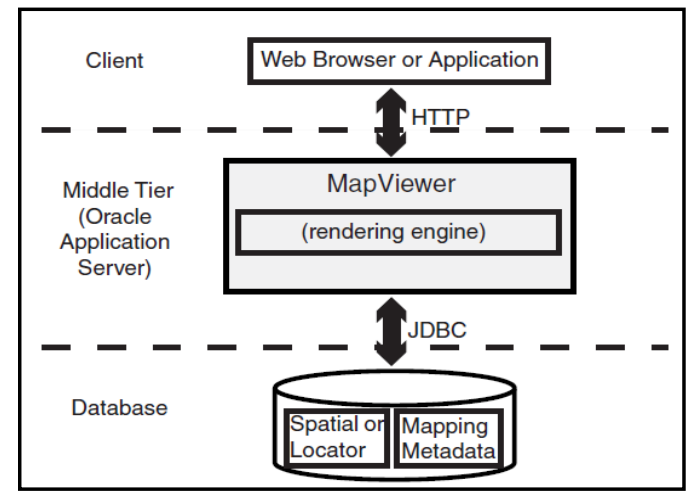

Figure 10: Basic concept of the MapViewer service

\section{Simulation of traffic}

In the Czech Republic selected engines are equipped with communication terminals, which periodically transmit operational data containing also current GPS coordinates. When the rolling stock is in motion, this communication terminal transmits the information with position details every 30 seconds.

The proposed simulation model contains the discrete simulation core using standard calendar of processes, on the basis of which individual events are performed - based on their time stamp. This simulation model was subsequently implemented in the demonstration application InfraRail.

Simulation of rolling stock operation can be divided into two parts. Simulation on the basis of:

- realistic historical data (operation emulation),

- generated data.

The simulation based on the generated data enables to simulate scenarios, such as running of two trains in the opposite direction on single-track lines, which will be a subject of further research. Figure 11 presents a running demonstration application in a situation, when a rolling stock moves on a single-track line section between two stations.

\section{Conclusion}

Infrastructure models present an inseparable part of the rail transport segment. These models can subsequently be used in a whole spectrum of approaches ranging from localization of the current position itself, obtaining operational information, and simulation of operation, to detection of non-standard or emergency situations. Generally mathematical structures graph is used with an advantage for transport infrastructure modelling. From the perspective of the processed domain's character it is possible to use a non-oriented graph, as the traffic on the individual railway segments (represented by edges) can be organized in any direction. Generally, a graph can e.g. be built in the operating memory with the use of appropriate data structure, or a specialized database tool can be used, that supports work with graph representations, such as e.g. the Oracle Spatial database. At the same time, it is possible to use specific operators and database machine functions to solve other application domains, such as e.g. evaluation of information on the current position of the rolling stock related to the railway network model, or to perform simulation of transport elements. Next focus will be paid to detecting of various non-standard or emergency situations which will be the subject of further research. 


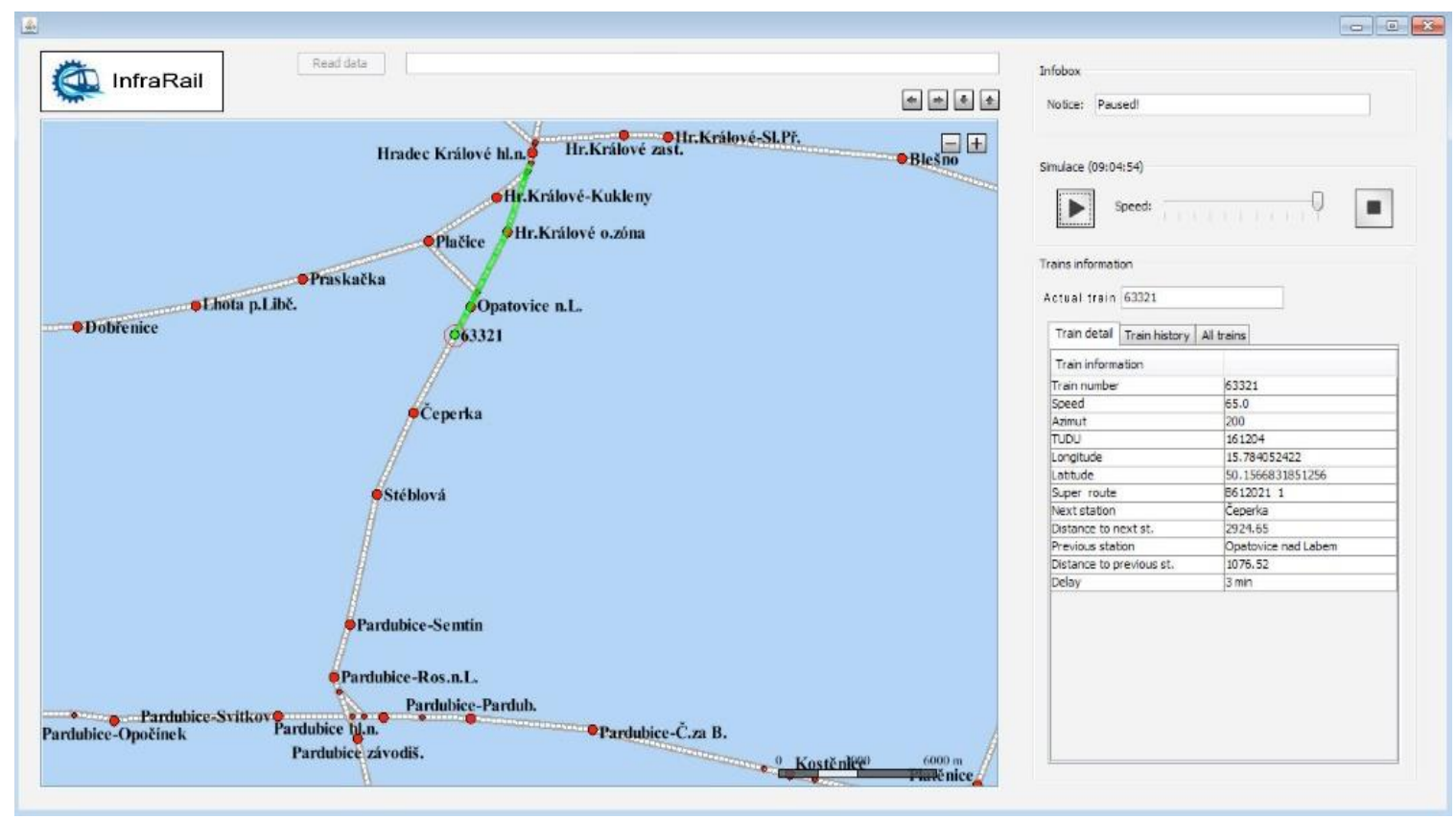

Figure 11: Running application

\section{Acknowledgments}

The work was supported from ERDF/ESF Cooperation in Applied Research between the Univ. of Pardubice and companies, in the Field of Positioning, Detection and Simulation Technology for Transport Systems PosiTrans (CZ.02.1.01/0.0/0.0/17_049/0008394).

\section{References}

Kom, (2011) - 144 - WHITE PAPER - A Roadmap to a Single European Transport Area - Creating a competitive and resource efficient transport system.

Giuninho, (2014) Low cost ERTMS implementation: ERTMS Regional. Railwaysignalling [online]. 2014 [cit. 2016-01-02]. http://www.railwaysignalling.eu/ertms-regional

Libbrecht, R. and H. Sturesson. (2005) LOCOPROL: Final Report [online]. 2005 [cit. 2015-06-10].: http://www.transport- research.info/Upload/Docu ments/200607/20060727_153639_69273_LOCOP ROL_Final_Report.pdf

Mouna, L. (2013) Integrated Applications Promotion Programme:

Train Integrated Safety Satellite System (3InSat) Demonstration

project, Rome 2013,[online]. [cit. 2015-06-10]. https://artes-apps.esa.int/sites/default/files/1IAP\%20ASTS\%203InSat_18-04-2013.pdf

Redding, L. (2014) Satloc: a high-tech saviour for lowdensity lines. Railjournal [online]. UK, 2014 [cit. 2016-01-02]. http://www.railjournal.com/index.php/teleco $\mathrm{ms} / \mathrm{satloc}$-a-high-tech-saviour-for-lowdensity-lines.html?channel=533

Dorazil, P. (2014) Základní vlastnosti kolejových obvodů bez izolovaných styků. Pardubice, 2008. Bachelor thesis. University of Pardubice. Supervisor: Milan Kunhart.

Kolář, P (2014). Řízení provozu na vedlejších železničních tratích. Seminář ZČU Plzeň-Fakulta elektrotechnická [online]. 2014 [cit. 2014-12-12]. http://old.fel.zcu.cz/Data/documents/sem_de_201 4/5-RB_Kolar.pdf

Kothuri, R. A A. Godfrind A E. Beinat. (2007) Pro Oracle Spatial for Oracle database 11g. New York, NY: Distributed to the book trade worldwideby Springer-Verlag New York, c2007, xxxiv, 787 p. ISBN 1590598997

Kothuri, R. et al. (2007) Pro Oracle Spatial for Oracle database 11g. New York, NY: Distributed to the book trade worldwideby Springer-Verlag New York, c2007, xxxiv, 787 p. ISBN 15-905-9899-7.

Murray, Ch. et al. (2006) Oracle ${ }^{\circledR}$ Spatial : Topology and Network Data Models $10 \mathrm{~g}$ Release 2 (10.2) [online]. 2006 [cit. 2012-07-09]. Available from : http://docs.oracle.com/cd/B19306_01/appdev.102/ b14256.pdf

Murray, Ch, et al. (2010) ORACLE® Fusion Middleware : User's Guide for ORACLE MapViewer 11g Release 1 (11.1.1) [online]. 2010 [cit. 2012-07-09]. Dostupné z: http://docs.ORACLE.com/cd/E14571_01/web.1111/e1 0145.pdf 